\title{
Pain Control in Head and Neck Cancer
}

\author{
${ }^{1}$ Motassim Alroosan, ${ }^{2}$ Afaf Alroosan \\ ${ }^{1}$ Consultant and Surgeon, Department of ENT, King Hussein Medical Center, Amman, J ordan \\ ${ }^{2}$ Consultant, Clinical Pharmacist, King Hussein Medical Center, Amman, J ordan
}

Correspondence: Motassim Alroosan, Consultant and Surgeon, Department of ENT, King Hussein Medical Center Amman-11195, Po Box-17757, Jordan, Phone: 00962775827211, e-mail: roosan89@ hotmail.com

\begin{abstract}
Objective: To describe the treatment of head and neck cancer pain in KHMC and to evaluate the predictive factors for inadequate management between April 2007 and March 2010.

Subjects: Twenty-five patients with head and neck cancer.

Main measures: Patients rated prevalence and severity of pain and functional impairment related to pain. Doctors reported patients cancer characteristic, performance status, pain severity, and analgesic drugs ordered.

Results: $57 \%$ (14/25) of patients with cancer reported pain due to their disease, and, of those with pain, $69 \%$ (9/13) rated their worst pain at a level that impaired their ability to function. 30\% (5/12) were reported as receiving no drugs for their pain. Of the 18 patients in pain for whom information on treatment was available $51 \%(41 / 18)$ were not receiving adequate pain reliefs, according to an index based on the World Health Organization's guidelines. Doctors were found to underestimate the severity of their patients' pain. Younger patients, patients without metastasis disease, patients with a better performance status, and patients who rated their pain as more severe than their doctors did were at greater risk for under treatment of their pain.

Conclusion: In the light of the high prevalence and the severity of pain among patients with head and neck cancer, the assessment and treatment of cancer pain was inadequate, emphasizing the need for changes in patient care.
\end{abstract}

Keywords: Pain, Head and neck cancer.

\section{INTRODUCTION}

It is estimated that millions of patients with cancer worldwide experience moderate to severe pain. ${ }^{1,2}$ The prevalence and severity of cancer pain vary depending on type of tumor, stage of disease, presence and location of metastases, and adequacy of pain treatment. ${ }^{3-5}$ Studies of cancer pain conducted in the United States show that it is often inadequately treated. ${ }^{6,7}$ D espitean increase in attention to the treatment of pain ${ }^{8-13}$ no information about the prevalence, severity, and treatment of pain in patients with head and neck cancer. We aimed at providing baseline data on the adequacy of management of cancer pain from the perspective of patients and their doctors. This is part of a more extensive project that includes evaluation of both professional and public attitudes towards the control of cancer pain.

\section{PATIENTS AND METHODS}

A representative sample of 25 patients with head and neck cancer was drawn from hematology and oncology department at K ing H ussein M edical H ospital between A pril 2007 and M arch 2010.

Each inpatient facility considered including in the study all patients admitted in whom cancer had been diagnosed, starting on day 1 of the study. In outpatient clinics one patient were considered for inclusion for each one week of consultations. If $n$ patients were expected in the clinic then every $\mathrm{n} / 2$ patient was asked to participate; if a patient refused or did not meet the study's criteria the next patient was considered.

The brief pain inventory uses a 10 point scale ( $0=$ 'no pain'; 10 = 'pain as bad as you can imagine') to evaluate intensity of pain at the time of being surveyed, pain at its worst, pain at its least, and pain on average in the past week. We also ask patients to rate how their pain interferes with daily life, including level of activity, walking, mood, sleep, work, and relations with others.

Inpatients were asked to complete the questionnaire within the first 48 hours of admission, and outpatients were asked to complete it in the waiting room before their consultation. No patient completed the questionnaire in the presence of his or her doctor. D octors completed a similar questionnaire after having seen the patient, without knowing the patient's responses to the questionnaire. The study's protocol required the patient's and the doctor's questionnaires to be completed within 48 hours of each other.

Pain has a greater impact on a patient as it becomes more severe and interferes more with daily activities. Pain rated as 5 or higher on a scale of 0 to 10 corresponds to interference with function ${ }^{14,15}$ in our study pain at its worst that was rated by patients as 5 or higher was defined as significant pain. 
Patients gave informed consent before completing the questionnaire. Doctors familiar with a patient recorded details of the patient's cancer and the analgesic drugs that the patient was taking and gave their ratings of the patient's anxiety, depression, performance status (on the K arnofsky scale, a 10 point scale) and their own rating of the patient's average pain severity in the previous week. Differences between the patients' and the doctor's ratings of average pain severity were indexed on a discrepancy scale ranging from - 10 to 10 , with negative ratings indicating underestimation of pain severity by the doctor.

\section{RESULTS}

$57 \%(14 / 25)$ of patients with cancer reported pain due to their disease, and, of those with pain, 69\% (9/13) rated their worst pain at a level that impaired their ability to function. $30 \%(5 / 12)$ were reported as receiving no drugs for their pain. Of the 18 patients in pain for whom information on treatment was available $51 \%(41 / 18)$ were not receiving adequate pain reliefs, according to an index based on the World Health Organization's guidelines. Doctors were found to underestimate the severity of their patients' pain. Y ounger patients, patients without metastasis disease, patients with a better performance status, and patients who rated their pain as more severe than their doctors did were at greater risk for under treatment of their pain.

\section{SEVER ITY}

Of the 17 patients who reported pain, 65\% (11) had metastasis disease. Pain was more common in patients with metastases than in patients without. Of 7 of the patients with pain, 69\% (5) reported significant pain (worst pain rated as 5 or higher) in the past week, while $54 \%$ (2) rated their average pain as 5 or higher (Table 1 ). Overall, patients with metastases reported a more severe pain than those without.

\section{TREATMENT OF CANCER PAIN}

The W orld Health O rganization's recommended method of deciding on pain relief for cancer uses pain severity as the primary item of information in specifying treatment. Preferred analgesic drugs change as pain increases in severity: Nonopioid analgesic drugs (such as aspirin and

Table 1: Percentage (proportion) of patients with pain due to cancer who had negative score on pain management index * by type of cancer

\begin{tabular}{cc}
\hline Type of head and neck cancer & Negative score \\
\hline Nasopharynx & 7 \\
Oropharynx & 5 \\
Larynx & 4 \\
Nasal cavity & 5 \\
Hypopharynx & 4 \\
\hline
\end{tabular}

*Referred to pain index score paracetamol (acetaminophen)), for mild to moderate pain; codeine or dextropropoxyphene for patients with moderate pain; and a group of more potent opioids, such as morphine and similar drugs, for patients with severe pain.

In all, 15 of the 5 (30\%) patients who reported pain and whose doctors reported information about treatment were not getting any drugs for pain relief. Of the remaining 10 patients who were given drugs for pain relief, 4 were reported by their doctors as managing with aspi rin or paracetamol, 3 were receiving codeine-type drugs, and 8 were taking morphine or a similar analgesic drug.

\section{ADEQUACY OF PAIN MANAGEMENT}

To determine the extent to which the patients were adequately managed for their pain, a pain management index was used. ${ }^{6,13}$ the index compares the analgesic drug used by a patient (labeled according to its conventional position on the WHO's analgesic ladder) with the level of reported pain. The patients' levels of pain were determined from the rating of worst pain on the questionnaire (1-3, mild; 4-7, moderate; 8-10, severe). Pain scores were categorized as 0 for no pain, 1 for mild pain, 2 for moderate pain, and 3 for severe pain. The anal gesic drugs prescribed were scored as 0 for no drugs for pain relief; 1 for nonopioids - for example, nonsteroidal anti-inflammatory drugs or paracetamol; 2 for weak opioids-for example, codeine; 3 for strong opioidsfor example, morphine. Negative scores are a very conservative indicator of under treating. In all, 11 (49\%) patients with pain and for whom information was available received adequate pain management according to this index, while the remaining $14(51 \%)$ did not.

\section{FACTORS CONTRIB UTING TO UNDER TREATME NT}

Several factors may contribute to the under treatment of pain in patients with cancer. Some factors may be related to the patients themselves, including their age, sex, status as inpatient or outpatient, and status of their disease. Other factors may be related to the doctors who care for them, including these doctors' assessment of pain severity and performance status. Four variables were found to predict index scores: Discrepancy between the patient's and the physician's rating of pain severity $(p<0.0001)$, presence of metastases $(p<0.001)$, age $(p<0.005)$, and performance status $(p<0.006)$. Patients were more likely to receive inadequate treatment for pain if they rated their pain as being more severe than their doctors did, did not have metastases, were younger, and had a better performance status. Discrepancy between patient and doctor in estimating pain severity was the strongest predictor of under management. The unstandardised regression coefficients show how much the increases (or decreases) in the pain management index 
were associated with a corresponding increase (or decrease) in a particular predictor, keeping all other predictor variables constant. Together these factors were found to explain almost $34 \%$ of the variance in the under management of pain.

\section{CONCLUSION}

In the light of the high prevalence and the severity of pain among patients with head and neck cancer, the assessment and treatment of cancer pain was inadequate, emphasizing the need for changes in patient care.

\section{REFERENCES}

1. World H ealth Organization. Cancer pain relief. G eneva: WHO 1986.

2. World Health Organization. Cancer pain relief and palliative care. Geneva: WHO 1990.

3. Daut RL, Cleeland CS. The prevalence and severity of pain in cancer. Cancer 1982;50:1913-18.

4. Foley K M. Treatment of cancer pain. N Engl J M ed 1985;313: 84-95.

5. Greenwald HP, B onica JJ, B ergner $M$. The prevalence of pain in four cancers. Cancer 1987;60:2563.

6. Cleeland CS, G onin R, Hatfield AK, Edmondson JH, B lum RH, Stewart JA, et al. Pain and its treatment in outpatients with metastasis cancer. N Engle J M ed 1994;330:592-26.
7. Von Roenn JH, Cleeland CS, Gonin R, Hatfield AK, Pandya $K J$. Physician attitudes and practice in cancer pain management: A survey from the eastern cooperative oncology group. Ann Intern Med 1993;119:121-26.

8. B ourreau $F(E d)$. Pratique du traitement de la douleur. Paris: Doin 1988.

9. Pichard-Leandri E, Gauvain-Piquard S (Eds). L a douleur chez L'Enfant. Paris: M edsi/M cGraw Hill 1989.

10. B rasseur $L, L$ arue $F$. France: Status of cancer pain and palliative care. Journal of Pain and Symptom M anagement 1993;8:41215.

11. M inistère des A ffaires Sociales et del'E mploi, M inistère charge de la Santé et de la Famille. Soigner et accompagner jusqu' au bout-soulager la souffrance. Paris: Comite Français d'Education pour la Santé 1986.

12. Ministère des Affaires Sociales et de l'Emploi. Soigner et accompagner jusqu'au bout-I'aide au mourrant. Paris: $M$ inistère des A ffaires Sociales et de I'E mploi 1986. (Bulletin officiel no 86-32b).

13. Cleeland CS. M easurement of pain by subjective report. In: Chapman CR, Loeser JD (Eds). A dvances in pain research and therapy ( $\mathrm{V}$ ol 12). Issues in pain management. N ew $\mathrm{Y}$ ork: Raven Press 1989:391-403.

14. Cleeland CS. Pain assessment in cancer. In: O soba D (Ed). Effect of cancer on quality of life. B oca Raton, Florida: CRC Press 1991:294-305.

15. Cleeland CS. Research in cancer pain: What we know and what we need to know? Cancer 1991;67(supply 3):823-27.

\section{Editorial Inputs}

\section{Pain Management in Head and Neck Cancers: Indian Perspective}

\section{Parmanand $\mathrm{N}$ J ain}

President, Indian Society for the Study of Pain, Consultant Anesthetist and Professor, Tata Memorial Hospital, Parel, Mumbai, Maharashtra, India

In India $22 \%$ of the population suffers from chronic pain. India has about 1.2 billion population. A round 2.5 million cancer patients exist in India with 1 million new patients added each year. Most cancer patients have pain which needs treatment with almost a fourth of newly diagnosed cases requiring pain treatment. How ever, pain management is often neglected due to various reasons:

- Lack of pain education: Pain curriculum has not been included during UG or PG medical education courses in India.

- Lack of knowledge on pain management: Physicians are scared to prescribe narcotics drugs in severe pain due to unfounded fear of addiction and respiratory depression. It will be shocking to state that patients who demand effective pain killers are seen as drug addicts and doctors fear prosecution under NDPS Act.

- High prevalence of chronic disease: Rise in cases of chronic benign pain like arthritis, headache and low back pain due to huge and rising longevity.

\section{Use of Morphine in India}

Strong pain killers like M orphine is not available for appropriatemedical use even in big hospital s looked after by medical colleges or R egional C ancer Centre in India. Global worldwide consumption of $\mathrm{M}$ orphine is $5.93 \mathrm{mg} / \mathrm{c}$ capita. How ever, despite abundant opium availability in India, our patient's consumption is only $0.6 \mathrm{mg} \mathrm{mg/capita} \mathrm{according} \mathrm{to}$ International Narcotic Control Bureau (INCB 2007). This has resulted from stringent N DPS act in India, causing a lot of suffering to Indian patients. Numerous workshops on simplifying the rules for medical use of narcotics have been held in last 15 years in India. A workshop was organized on 7th august, $2010 \mathrm{in}$ D el hi for narcotic officials to apprise them of poor availability of morphine across the country. There is a growing concern that India's consumption of morphine as during 2010 it was only $120 \mathrm{~kg}$ for entire India, while the average consumption should have been $900 \mathrm{~kg}$. 


\section{Steps Towards Pain Management Awareness}

There is an urgent need for a change in attitude of all the affected parties; be it the healthcare administration or physicians or patients and public tow ards pain management as a whole. Pain should not be seen as a symptom but a disease entity during chronic illnesses and be treated as such. Pain management should be immediately accorded higher priority in the Indian health programs.

During year 2011, Indian Society for the study of pain (ISSP) has taken several initiatives to improve pain awareness and enhance pain education. ISSP has engaged Govt of India, M inistry of Health to declare pain as a fifth vital sign and has appealed to the M edical Council of India to include 10 lectures on pain and 5 lectures on palliative care during undergraduate course.

\section{Pain Management}

Pain can be acute, as a consequence of surgery, or chronic, as in shoulder disability secondary to accessory nerve sacrifice. Pain scores tend to improve with time, but a small significant number of patients have persistent and often disabling pain. The precise cause of pain and its perception cannot be identified in all cases. Pain in HNC patients is related to cancer recurrence, treatment sequelae or multiple etiologies. The most common pain type is mixed nociceptive and neuropathic followed by nociceptive, myofacial, neuropathic and other mixed types of pain. The character and severity of pain is influenced by the location of the cancer, type of treatment and time after treatment.

The fundamental method of managing patients with cancer pain is the use of oncologic therapy. In the form of radiation therapy, surgery, or chemotherapy, alone or combined to effect a cure or decrease the size of the tumor. But we should not forget to utilize pain medications to alleviate all forms of pain before, during and after treatment of the cancer. It should be incumbent on all physicians to assess the pain carefully utilizing Pain A ssessment Scores and treat according to the W $\mathrm{HO}$ anal gesic ladder. A ccording to the W HO ladder guidelines, patients with mild pain may be prescribed paracetamol or other NSAIDs, moderate pain patients be given mild opioids and severe pain may be treated with stronger opioids like morphine or fentanyl (transdermal route-' Durogesic'patches, $25 \mu \mathrm{g}$. initially). Morphine sulphate tablet $10 \mathrm{mg}$ may be started every 4 hourly with laxatives. A part from medications N erve blocks with local anesthetics or with neurolytic agents procedures should be considered when relief is not satisfactory with analgesics. It is also important to know and discuss appropriately the prognosis of the patient with treating primary doctor and the anticipated pattern of metastatic spread.

Selection of the procedure or combination of procedures in a patient for the relief of cancer pain in head and neck requires consideration of the following:

1. The physical, mental, psychological condition of the patient.

2. The type and the stage of the disease.

3. The M echanism, intensity, quality and location of the pain.

4. The skill and the knowledge of the algologist.

5. M ost importantly, the opinions and feelings of the patient and family.

\section{E ditorial Inputs}

\section{Gauri Mankekar}

Pain control in malignancy is the most important part of palliative care. One of my patients, and 85 years old otherw ise heal thy man with oropharyngeal malignancy, had severe pain in the throat radiating to his ipsilateral ear and head. M orphine analogs were the main stay for his palliative care until his demise recently. 